\title{
Presentation
}

\section{Historicizing Brazil's Great Acceleration}

\section{Apresentação}

Escrevendo a história da Grande Aceleração no Brasil

Antoine ACKER https://orcid.org/0000-0002-2698-359X

Department of History

University of Zurich

Karl Schmid-Strasse 4, CH-8.006 Zurich, Switzerland

antoine.acker@hist.uzh.ch

GEORG FISCHER http://orcid.org/0000-0003-4791-5884

Department of Global Studies

Aarhus University

Jens Chr. Skous Vej 7, 8.000 Aarhus C, Denmark

fischer@cas.au.dk

In the second half of the twentieth century, global resource use, landscape transformation and greenhouse gas emissions have acquired unprecedented dimensions - the world has experienced a "Great Acceleration". This process was particularly spectacular in a few fast-industrializing regions of the Global South. In global environmental history and in the geosciences, the Great Acceleration has become a common notion to delineate a particular period - if not the beginning - of the Anthropocene, the era in which humans became geological agents (McNeill; Engelke, 2014; Steffen et al., 2015). This special issue of Varia Historia analyzes how Brazilian society both contributed to and faced the consequences of the Great Acceleration as a global phenomenon.

Received: 19 Mar. 2018 | Accepted: 23 Mar. 2018

http://dx.doi.org/10.1590/0104-87752018000200002

Varia Historia, Belo Horizonte, vol. 34, n. 65, p. 307-314, mai/ago 2018 
We hope to provide useful suggestions on how to write the history of the Great Acceleration by focusing on hydroelectric dams, agricultural techniques, oil consumption, science and economic valorization, transport infrastructure and landscape perception. The expansion of transport and energy infrastructure as well as the introduction of new farming and mining technologies have been at the heart of Brazilian developmentalist politics. Highways, dams, refineries, industrial complexes, giant mining sites and even state-planned agricultural schemes were ways to territorialize state power in association with the expansion of the capitalist economy. By disentangling some of these processes, this issue aims at refining our understanding of the interplay between culture, science, technology, politics and the environment in the adoption of new regimes of resource use.

Writing the history of the Great Acceleration requires us to carefully weigh causalities and consequences without resorting to teleological explanations. In their The Great Acceleration, John McNeill and Peter Engelke (2014) place "push factors" at the basis of the Great Acceleration process: the demand for more energy deriving from demographic and economic growth as well as war. Indeed, migration, urbanization, resource conflicts, all seem derivative of global population growth. Yet the main finding of this special issue is that "pull factors" were at least as decisive in triggering the Great Acceleration. By this we mean available technology, scientific discourses, ideologies and policies of modernization as well as the aesthetic perception of landscapes. On the one hand, the commodities of the Great Acceleration needed "routes of power" to be extracted, produced, channeled and distributed to consumers (Jones, 2014). New transport systems, availability of capital, techniques of soil “improvement", industrial machinery, energy networks and modern household equipment all contributed to the creation of standards, expectations and needs which propelled the acceleration of consumption and production. On the other hand, the Great Acceleration also emerged out of new knowledge and ideologies that constituted an "Anthropocene culture" (Pádua, 2017). Scientific triumphalism, modernization discourses, and representations of space (the "March to the West" 
toward the Cerrado in the 1940s or the "land without people for people without land" which accompanied the colonization of Amazon valley) were catalysts of this culture. They not only encouraged Brazilians to accelerate the exploitation of nature, but also signalized Brazil's availability as a raw material provider for global markets.

We argue for an approach that combines structural dimensions with a decidedly praxeological perspective, recognizing the agency of people embedded in power constellations and institutional settings. What is particularly important to us is the question of how technology, discourse and practice intertwined to produce new material demands and new cultural significations of nature. Did a specific way of speaking and thinking about nature and material abundance induce a notion of plenty and availability? Is the transition from a discourse of scarcity to a discourse of plenty the key to understand the jump into the Great Acceleration? What effect did technological change have on these discourses? What social psychologist Harald Welzer (2011) has fittingly termed "mental infrastructures", a cognitive appropriation of the world, which takes the technologically mediated, boundless availability of nature for granted, reminds us that the Great Acceleration belongs to the history of mentalities as much as to economic history or the history of technology. In line with this perspective, Thomas Mougey shows in his contribution to this special issue that scientific engagement with the Amazon valley preceded the global rise in demand for rainforest commodities in elaborating big plans for the region's economic development. In his article, Claiton da Silva argues that scientific knowledge on fertilization and acclimatization of soy crops was the decisive factor that unleashed the Great Acceleration in the Cerrado. By looking at the frustrations that oil import restrictions generated during the Second World War, Natascha Otoya, in her contribution to this issue, demonstrates how the availability of oil had created new habits of mobility and a new dependency on energy.

These contributions also highlight the role played by local contexts in the making of Anthropocenic models, showing good reasons to descend from the heights in which existing scholarship on the Great Acceleration has operated. The human footprint on the planet is not homogeneous, 
but differentiated. As McNeill and Engelke recognize, an inhabitant of the UK in the twentieth century produced more carbon emissions than one of Kabul, and an inhabitant of Kabul himself probably contributed more to pollution than someone from a remote Afghan village. This is even more true for Brazil, sometimes ironically re-baptized "Belíndia" (Belgium/India) or "Dinamália” (Denmark/Somalia) to stress the differences in development levels within the country. The unevenness of Brazil's socio-environmental landscapes regarding their position in the history of the Great Acceleration calls for a new research agenda, which should consist in at last including the Latin American, African and Asian continents in the Anthropocenic narrative. While the so-called industrialized world (mainly North America, Europe and Japan) has held a central position in the explanatory frameworks of the Anthropocene, formerly colonized territories have remained a peripheral part of the story. Shall we assume that they have been mere suppliers of raw material to the global economy, or at best late reproducers of the Anthropocenic standards of their former colonizers? Brazil's Great Acceleration hints at a much more complex story.

Brazil, along with countries in other world regions, occupies a peculiar, double-edged position in the Anthropocene. On the one hand, as a major supplier of natural resources, it holds a peripheral economic position. It provided a significant share of the material basis of the global Great Acceleration, but value was added elsewhere. Its commodities contributed to the post-war industrial development of countries like Japan and West Germany and, consequently, to the emergence of the hyper-consumerist, auto-mobile and carbon-intensive culture of our times. Brazil's agrarian sector has been subject to global market pressures, fueling the devastation of tropical forests and fostering the destruction of livelihoods of peoples who traditionally rely on a minimal ecological footprint. The same is true for the Northeast, where global climate change aggravates the problem of drought.

On the other hand, Brazilian upper and (until recently fast-growing) middle-classes have been running fast on the path toward U.S. consumption standards. Brazil, with its state-led industries and R\&D agencies, has also played an active role in co-developing technologies that 
are key to large-scale environmental destruction. The Brazilian biofuel and aeronautic industries are telling examples of this, as is Brazil's contribution to "tough oil", a set of high risk technologies used to reach the world's last oil reserves due to the exhaustion of conventional wells (LeMenager, 2014). The state oil company Petrobras is credited to be a world leader in offshore drilling technologies developed for the pre-salt province, which, concealed by the opacity of the deep sea, have devastating impacts on marine wildlife. Warnings by climate scientists that, in order to keep global temperature rise within manageable boundaries, humankind cannot afford to burn the known fossil energy sources, are ignored by almost all political camps in Brazil. The recent softening of the rules on foreign participation in the "Pré-Sal" will likely further accelerate the exploitation of deep-sea oil with less state control. Besides, Petrobras' move toward foreign oil fields since the 1970s has created new post-colonial contexts in which the country finds itself in a historically reversed position. In Africa, the Middle East and other Latin American countries, Brazilian companies seek profits by putting other environments at risk.

Whereas the Great Acceleration has been proposed as a piece in the puzzle of finding a periodization for the Anthropocene, the identification of its beginnings, ends, continuities and ruptures presents some interesting challenges in itself, as this issue shows. As Claiton da Silva argues, in the case of soy, the Great Acceleration was exponential and tended to grow ever faster in the last decades of the twentieth century. Here the notion of a "rupture" induced by techno-scientific change seems adequate. However, other contributions demonstrate that the techno-political apparatus that permitted the Great Acceleration in other fields started to be assembled earlier. Hydropower came to be seen as Brazil's energetic future already in the nineteenth century, as Nathalia Capellini emphasizes in this issue. In each case, we have to ask what were the constellations that opened windows of opportunities for the adoption of new regimes of resource exploitation and consumption.

These dynamics represent no necessary outcomes of modernization processes or the mechanistic unfolding of capitalist socio-environmental 
relations. The history of the exploitation and waste of nature is a history of agency, negotiation and conflict. There is a political agenda of the Great Acceleration, which does not coincide with material transformation, but often precedes or accompanies it. Arguably, the ruling period of Getúlio Vargas (1930-1945 and 1951-1954) saw a "political acceleration": The expansion of central government and institutionalized planning procedures were instrumental for the realization of large-scale infrastructure projects, greater involvement of science in government and economic policies privileging industry and mechanized agriculture. However, Vargas' developmentalism did not emerge from a vacuum. Dreams of state-led industrialization can be found in congressional speeches in the early Republic, and domination of nature by technology was a long-standing wish of Brazilian engineers and politicians alike, as is evident, for instance, in the debates following the great drought in the Northeast in the 1870 s.

For the post-Second World War period, which is at the center of this issue, different moments were particularly significant for Brazil's Great Acceleration. On the symbolic level, Kubitschek's presidency stands out: He proclaimed "acceleration" as his key political project by promising "50 years [of progress] in five". An embodiment of this agenda is, of course, Brasília, a stunning project of accelerated urban development. Similarly, the military regime used the iconicity of power plants, transport infrastructure and farming machinery to brand itself as modern. In the absence of democratic liberties and social equality, "growth" became the regime's main resource for legitimation. Later, the PT governments embedded their ideals of social redistribution within discourses of growth and progress revolving around accelerating things, as can be seen, for instance, in the "Programa de Aceleração do Crescimento". However, we should not assume a direct transmission line between political discourse and the accelerating materialization of infrastructure. In fact, the building of infrastructure could be remarkably slow, and taking the step from planning to construction could last decades. As a result, large technological systems could acquire new economic functions, as Georg Fischer argues, in this issue, regarding the Estrada de 
Ferro Vitória a Minas, or new political meanings, as in the case of the Belo Monte Dam, a planning relict of the military regime.

The history of the Great Acceleration has to take into account conjunctures of knowledge production and shifts in nature-society relations at large. Ideas about the management of natural resources have changed over time. A case in point are agrochemicals, whose effects on ecosystems were considered positive until the 1970s: They would make nature "sounder" by reinforcing the humus, while for many conservationists and scientists the real "enemy of nature" was the caboclo practicing small-scale slash-and-burn, destroying forest patches and fostering soil erosion. Similarly, petroleum, highways and automobiles were welcome as a "clean" alternative to fuelwood, railroads and trains, which Brazilian administrations and scientists deemed dangerous agents of deforestation. The association between oil and environmental toxicity would only emerge in the 1970s, with the growing popular perception of a global climate crisis, nourished by updated scientific knowledge about the relation between $\mathrm{CO} 2$ and climate change.

What does it take for humans to realize the damage they do to Earth, or at least to the ecosystem in which they live? Does it take until a human population has exhausted its livelihood to the point of threating its own existence, as environmental historian Donald Worster writes in the light of past examples of "ecological surprises" which badly affected Pleistocene hunters and ancient Mesopotamians (Worster, 1994)? Indeed, the historical problem that lies behind the concept of the Great Acceleration is precisely that twentieth-century humans were unable to identify the tipping point after which their intervention on ecosystems became a planetary force unleashing irreversible environmental catastrophes. Brazil is a good example to reflect on this change of scale because of the stunning rapidity with which the country turned its back on traditional forms of extractivism to embrace Anthropocenic production and consumption. The articles of the present issue look at processes of energy transitions, land use change and industrialization, the understanding of which helps situate the Great Acceleration in a long-term perspective and identify crucial shifts toward irreversible environmental change. 
While this approach might seem pessimistic, we do not forget Brazil's strong tradition of socio-environmental resistance, which is vivid today despite a very difficult political climate. Indeed, there is still much to preserve: Brazil hosts up to $20 \%$ of the global biodiversity stock, around $30 \%$ of the world's tropical forests and $12 \%$ of its freshwater (Pádua, 2017). Indigenous peoples, riverine dwellers, rubber tappers, quilombolas, "sem-terras" and other groups have reframed traditional forms of extraction and agriculture as local solutions for a solidary and sustainable future. These solutions must be part of the global effort to avoid a new change of scale in the Great Acceleration. By trying to understand why humans failed to detect the moment when exploitation of nature started to turn into overexploitation, menacing their own livelihood, we hope to contribute to another part of this effort.

\section{BIBLIOGRAPHICAL REFERENCES}

JONES, Christopher F. Routes of Power: Energy and Modern America. Cambridge, Mass.; London: Cambridge University Press, 2014.

LEMENAGER, Stephanie. Living Oil: Petroleum Culture in the American Century. New York: Oxford University Press, 2014.

MCNEILL, John R.; ENGELKE, Peter. The Great Acceleration: an Environmental History of the Anthropocene since 1945. Cambridge, Mass.: Belknap Press of Harvard University Press, 2014.

PÁDUA, José Augusto. Brazil in the History of the Anthropocene. In: ISSBERNER, Liz-Rejane; LÉNA, Philippe (Org.). Brazil in the Anthropocene: Conflicts between Predatory Development and Environmental Policies. London; New York: Routledge, 2017. p.19-40.

STEFFEN, Will, et al. The Trajectory of the Anthropocene: the Great Acceleration. The Anthropocene Review, vol. 2, n. 1, p.81-98, 2015.

WELZER, Harald. Mental Infrastructures: How Growth Entered the World and Our Souls. Berlin: Heinrich Böll Foundation, 2011.

WORSTER, Donald. The Wealth of Nature: Environmental History and the Ecological Imagination New York; Oxford: Oxford University Press, 1994. 